\title{
Does Cash Transfer Promote Market Citizenship?
}

\begin{abstract}
The most obvious conclusion of this book is that there is no single Turkish experience. Nor can we reach definitive once-and-for-all conclusions about the impact of CT as an instrument of social assistance. Comparison among our cases highlights variables grounded in local conditions and policy design that help determine the outcome of CT projects, and whose relevance extends far beyond Turkey. Among these are human and financial resources, but also of the capacity for local knowledge. When these allow consistent and appropriate targeting, CT can provide an important step in the direction of inclusion and equality in a market context. It would be misleading, however, to believe that this instrument on its own is sufficient. At the core of market citizenship is the dignity conferred not only by paying one's own way, but also by earning one's own way: CT instruments work best as a complement to, not replacement for, access to the official labor market.
\end{abstract}

Keywords Social cash transfer • Citizenship • Rights • Outcomes • Labor market

The case studies presented in this book warn us away from any premature reification of national models, let alone of CT itself. We are brought back

(C) The Author(s) 2021

C. Ark-Yıldırım, M. Smyrl, Social Cash Transfer in Turkey, https://doi.org/10.1007/978-3-030-70381-3_7 
instead to one of the starting points of this enquiry, the notion of policy instruments as tools:

To say that something is a tool is to say that it can produce certain results under appropriate circumstances; it is not to say that it is drilling, sawing, or welding at any particular moment. (Majone and Wildavsky 1979: 169)

What, then, are the appropriate circumstances in this case?

\section{Conditions of Success}

CT is not social policy on the cheap; even less is it a retreat of the state. In terms of resources, the actual sums transferred are only a starting point. Successfully targeting, management, and monitoring requires more administrative and technical resources than in-kind distribution of equivalent scope, and this in turn demands that programs be designed on an adequate scale. The lack of resources that proved problematic in $\mathrm{R}$ is largely attributable to its size- too small for the SASF to have the internal resources to manage it directly or to be of real interest to private partners. Bigger, however, is not necessarily better. While a national network of financial services provided by Halkbank allowed the ESSN system to function smoothly, the unprecedented scale of the program and the need for multiple partners to work together to scale it up in a short time using necessarily incomplete information contributed to a system design centered on imperfect indicators of vulnerability. The high institutional startup costs of the system established a strong dynamic of path dependence, leading to this design being maintained even after the program's size had stabilized. Its sustainability should EU resources be withdrawn, finally, remains in question.

At any scale, information about the situation and needs of individuals is among the critical resources required for effective targeting. The cursory nature of home visits carried out by untrained inspectors in $\mathrm{R}$ contributed to inadequate information there. In the case of ESSN, officials interviewed claimed that training was provided for SASF inspectors, but the lack of any evidence for this in R suggests considerable local-level variation. A distinct set of challenges were unique to ESSN. The impossibility of knowing what, if any, assets migrant families might be able to access from Syria and the refusal of the Turkish government to allow implementing agencies full access to personal information contained in national databases combined 
to hinder any systematic in-depth evaluation of impact at the individual level. The contribution to successful targeting made by local knowledge in $\mathrm{U}$ provides the mirror image of these situations. Getting this right is critical. For CT to contribute to social citizenship, aid must go to those who need it the most; more than that, it must be seen as doing so. Suspicion of political favoritism, of cheating by recipients (systematically failing to report informal income, etc.), or of flawed indicators of vulnerability detract from the principle of rights founded on need.

A second critical feature emerging from the case studies is the importance of coherence. The design and implementation of a policy instrument is seldom the work of a single agency. Even when it is, the example of the SASFs suggests that agencies themselves can be collections of individuals with diverse points of view. The question is whether those involved share a common goal. Departures from consensus, as in the diverging interests of public and private partners evident in $\mathrm{R}$, detract from citizenship-enhancing outcomes. The case of ESSN is critical here for a number of reasons. Most obviously, the ambiguous consensus inherent in its origins influenced the conflict of goals evident in its implementation. Preventing migrants from reaching Europe and assisting the most vulnerable of them in Turkey are goals with at best imperfect overlap. Considering the presence of Syrians in Turkey as temporary or indefinite implies a different focus even in the short term. Integrating migrants into the labor market and restricting access to work permits is contradictory. All of these points of view, nevertheless, were present in one or another of the relevant Turkish, European, or International agencies. The persistent limits in the program's ability to reach all of the most vulnerable or to move participants beyond the most limited forms of market integration can largely be traced to this situation.

We must be careful, however, not to confuse the need for consensus on ends with other much less useful distinctions: those between public and private or between national and transnational.

A clear lesson of the case studies is the need to get beyond the increasingly sterile debate between empowerment and control. These are not contradictory; at the local level U illustrates high levels of both; R largely failed to accomplish either. The ESSN included elements of control through its registration and address requirements, but also measures of market empowerment through its use of unrestricted cash transfer. More importantly - and too often lost in the polemic over "rights-based citizenship"-all forms of citizenship imply a balance between empowerment and control, differing chiefly on the forms and locus of control. Premodern 
society placed it in the hands of "family, church, or lord" (Esping-Andersen 1990: 35); the turn to the market was in part a struggle for liberation against these. The ideal of "industrial citizenship," in turn, was a reaction to the perceived excesses of the market. It allowed a degree of decommodification but ushered in the control of civil servants, labor unions, or corporations. A market-centered approach offers yet another set of possibilities for striking this balance but, as illustrated in all of our cases, discretion and hierarchy can persist to the detriment of a fully rights-based model of market citizenship.

Another false dichotomy is between "public" and "private." How should we conceptualize the role of private companies such as Multinet, or of hybrid enterprises such as Halkbank when they are incorporated into policy and perform a public function? Both acted as for-profit policy subcontractors, and presumably in their own interests. The contrasting experience of $\mathrm{R}$ and ESSN, nevertheless, shows us that this is not systematically good or bad. Effectively integrating a private partner is a technical question of program design, not an ethical one of "corporate social responsibility." Even more vexing is any attempt to put parastatal bodies such as the SASFs or even the TRC into neat categories. Once again, what they do matters more than how they are labeled.

Similarly blurred boundaries are evident in the international sphere. How should we characterize the WFP? Formally a UN agency, it behaves as a not-for-profit corporation, competing for contracts and offering attractive careers in return for effective provision of services. On the public side, finally, there is no unified actor that can unambiguously be identified either with the Turkish state or with the European Union. In both domestic programs and the ESSN, Turkish public actors include local bodies and national agencies. Directorates found within a single ministry, can be the source of competing projects. The EU is represented in the ESSN by three distinct actors-political leaders for whom humanitarian budgets are a price worth paying to reach an agreement about migration, and the two DGs, ECHO and NEAR, with distinct missions, procedures, and internal cultures focusing, respectively on short-term humanitarian assistance, and medium-term development and national capacity-building.

Taking all of this together brings us back to the importance of coordination and consensus. What matters is not identity: public, private, charitable, international; any and all of these can work together effectively, as municipal authorities and civil society organizations did in U, or the WFP and TRC did in the case of ESSN. Whether they do so in practice in any given case proves to be among the most important indicators of policy success. 


\section{Social Citizenship in Context}

We began this book with a question: can market-enhancing instruments contribute to "equality of membership"? Our answer is cautiously positive. There is no doubt that, like the policy instruments of premodern and those of industrial societies, CT programs can be used as instruments of exclusion; some aspects of the experience of the ESSN illustrate this in direct and distressing ways. This does eliminate the potential of these same instruments to play a more constructive role. A very low-income family, whether Turkish or Syrian, given additional purchasing power through a digital CT card has a greater (albeit far from absolute) degree of autonomy in its consumption choices. More importantly, perhaps, the very act of purchasing necessities, rather than acquiring these through charitable gift or in-kind distribution, increases its integration into the economic and social life of its local community. The family's life is made more ordinary, in the sense of being more similar to that of its slightly better-off neighbors. As such, this can be seen as a small but significant step away from stigma and personal dependence. The degree of market integration is clearly different across our cases. The two local examples retained strong nonmarket controls over what could be purchased, and where. With ESSN, assistance can be drawn in cash, removing this particular element of control, but others remain; program participation is used as an incentive for migrants to register and to comply with restrictions on movement. Despite all of these limits, however, each in its own way represents a small step in the direction of market citizenship. There is no doubt that CT instruments can and frequently do serve as a force for social discipline, but this too is an element of membership. Market-enhancing instruments of social policy, CT among them, can contribute to social and economic inclusion - if they are deployed at an appropriate scale; if sufficient financial, technical, and social resources are available; if they offer stability in the medium term; and if the agencies central to policy design and implementation share the goal of inclusion and actively work together to promote it.

The contribution made by CT is real; it is also necessarily incomplete in the very logic of the market itself. CT programs contribute to empowering and integrating individuals as consumers, but fuller inclusion and true equality of membership in a market-centered society requires participation as workers. We are brought back to the historical anecdotes evoked in Chap. 2. It is less burdensome, as Montaigne reminds us, to purchase 
something than to receive it as a gift. True dignity in a market society, however, as the feminist movement of the 1970s rediscovered, implies earning one's own way. The final word goes to Frederick Douglas: "I am now my own master! The thought 'I can work for a living' placed me in a state of independence" (Shklar 1991: 83). Who better than a former slave to appreciate the market as a "social conquest" (Fontaine 2014).

In a coherent logic of market-enhancing policies, CT programs would go hand-in-hand with policies that facilitate fuller market participation, and in particular access to formal labor markets. To be effective, such policies require a significant degree of stability and medium-term legal security. Persons effectively limited to working in the informal sector or migrants uncertain of whether they will be able to remain in their host country are far from full membership, even in economic and social life. Critically, overcoming these barriers requires looking beyond the strictly economic sphere. In addition to economic support, integration into a market society requires an extension of legal rights which, to date, have been denied to the overwhelming majority of Syrian migrants in Turkey.

The ability to grant status, in the sense of legal rights, remains unique to states, and it turns out to be of the first importance. In the logic of Polanyi, politics defines the conditions in which markets operate, and accordingly determines the extent to which they can serve as instruments of inclusion. In the end, thus, we return to citizenship in the fullest sense. The final lesson of this study is that social and economic inclusion can indeed be pursued in advance of civil rights and political participation, but that these must ultimately follow. The interdependence among the elements of citizenship is inescapable. Cash transfer to very low income families is a useful step on the path leading ultimately to "market citizenship" as we have defined it, as effective equality of membership in a market society, but it is only a first step.

\section{REFERENCES}

Esping-Andersen, Gøsta. 1990. The Three Worlds of Welfare Capitalism. Cambridge, UK: Polity Press.

Fontaine, Laurence. 2014. Le Marché. Paris: Gallimard.

Majone, Giandomenico, and Aaron Wildavsky. 1979. Implementation as Evolution. In Implementation, ed. L. Pressman and W. Wildavsky, 3rd ed. Berkeley, USA: University of California Press. 1984.

Shklar, Judith. 1991. American Citizenship. Cambridge, MA: Harvard University Press. 
Open Access This chapter is licensed under the terms of the Creative Commons Attribution 4.0 International License (http://creativecommons.org/licenses/ by $/ 4.0 /$ ), which permits use, sharing, adaptation, distribution and reproduction in any medium or format, as long as you give appropriate credit to the original author(s) and the source, provide a link to the Creative Commons licence and indicate if changes were made.

The images or other third party material in this chapter are included in the chapter's Creative Commons licence, unless indicated otherwise in a credit line to the material. If material is not included in the chapter's Creative Commons licence and your intended use is not permitted by statutory regulation or exceeds the permitted use, you will need to obtain permission directly from the copyright holder. 